Journal of Pharmaceutical Science and Medical Research

Vol. 4, No.1, Februari 2021, hal $11-19$

ISSN (print): 2614-4840 ISSN (online): 2614-6118

Avaliable online at: http://e-journal.unipma.ac.id/index.php/pharmed

\title{
PERAN KELUARGA DALAM MENGHINDARI DAMPAK NEGATIF PENGGUNAAN GADGET PADA KESEHATAN MENTAL ANAK USIA SEKOLAH DI DESA DULANGON
}

\author{
Moh. Rizki Fauzan ${ }^{1}$, Ake Royke Calvin Langingi ${ }^{2}$, Fernando M. Mongkau ${ }^{3}$, Finni \\ Fitria Tumiwa ${ }^{4}$, Hairil Akbar ${ }^{5}$ \\ 1,5 Prodi S1 Kesehatan Masyarakat Institut Kesehatan dan Teknologi Graha Medika \\ ${ }^{2,4}$ Prodi S1 Keperawatan Institut Kesehatan dan Teknologi Graha Medika \\ ${ }^{3}$ Profesi Ners Institut Kesehatan dan Teknologi Graha Medika \\ Jl. Raya AKD RSI Moonow Lantai II, Mongkonai Barat, Kotamobagu \\ e-mail: mrrizkifauzan@gmail.com
}

\begin{abstract}
Abstrak
Gadget merupakan teknologi yang sangat populer sekarang ini, orang dewasa maupun anakanak menggunakan gadget, dimana banyak produk-produk gadget yang menjadikan anakanak sebagai target pasar mereka dan anak-anak kini telah menjadi konsumen aktif pengguna gadget. Dampak negatif penggunaan gadget yaitu dapat mengganggu kesehatan, menganggu perkembangan anak, mempengaruhi perilaku anak dan penurunan konsentrasi belajar. Peran keluarga yaitu menggambarkan perilaku, sifat dan kegiatan yang berhubungan dengan individu dalam situasi posisi tertentu. Tujuan Penelitian: Penelitian ini untuk mengetahui peran keluarga dalam menghindari dampak negatif peggunaan gadget pada kesehatan mental anak usia sekolah. Metode Penelitian: menggunakan metode deskriptif analitik dengan pendekatan cross sectional. Sampel menggunakan metode pengambilan Total sampling yaitu 51 keluarga yang memiliki anak usia 10-12 tahun. Penelitian ini menggunakan instrumen kuesioner dan analisa data menggunakan uji chi-square. Hasil penelitian: berdasarkan uji chi-square menunjukan adanya hubungan antara ke dua variabel dengan nilai $p=0,000$ kurang dari 0,05 . Kesimpulan: dari penelitian ini adalah ada hubungan antara peran keluarga dalam menghindari dampak negatif gadget pada kesehatan mental anak usia sekolah di Desa Dulangon Kecamatan Lolak.Saran: Diharapkan penelitian ini menjadi acuan bagi keluarga untuk selalu memperhatikan anaknya agar tidak selalu menggunakan gadget agar tidak berdampak buruk.
\end{abstract}

Kata kunci: Peran keluarga, penggunaan gadget, kesehatan mental

\section{RELATIONSHIPS THE ROLE OF FAMILY IN AVOIDING THE NEGATIVE IMPACT OF GADGET USING ON MENTAL HEALTH SCHOOL AGE CHILDREN IN DULANGON VILLAGE, KECAMATAN LOLAK}

\section{Abstract}

Gadgets are a very popular technology now, adults and children use gadgets, so many gadget products make children their target market and children are now active consumers of gadget users. The negative impact of using gadgets, could can interfere with health, disrupt children's development, affect children's behavior and decrease the learning concentration. The role of the familly that describer the pattern of behavior, the nature and activities associated with individuals in certain position situations. Research Objektive: This study is to determine the role of the family in avoiding the negative impact of using gadgets on the mental health of school age children.The Research Method : used descpritive analytical methods with a cross sectional appoarch. The Sample: Used the total sampling method, which is 51 families who have children aged 10-12 years old. This study used questionnaire instruments and data analysis by using the chi-square test.The results of the study: Based on the chi-square test showed a relationship between the two variable with a value of $p=0,000$ less than 0,05 . Conclusion : This study found a relationship between the role of family in avoiding the negative impact of gadgets on school-age children in Dulangon Village Districk. Suggestion : Hopefully, this research can be the reference for the family to pay attention to their children not to always use gadget in order not to give bad impacts to them.

Keywords: Family role, use of gadgets, mental health 


\section{Pendahuluan}

Kemajuan teknologi informasi dan komunikasi yang sangat pesat menuntut kita untuk jeli memilah dan memilih berbagai informasi yang kita terima. Salah satu dampak dari kemajuan teknologi adalah munculnya perangkat gadget berupa smartphone yang selain berguna sebagai sarana komunikasi juga bisa sebagai game. (Akbar, 2020)

Menurut World Health Organization (WHO) perkembangan teknologi dan informasi di dunia mengalami kemajuan yang sangat pesat, yang di tandai dengan kemajuan pada bidang informasi dan teknologi, bangsa indonesia merupakan salah satu bangsa yang ikut terlibat dalam kemajuan media informasi dan teknologi. Menurut World Health Organization (WHO) melaporkan bahwa 5-25\% dari anak-anak usia sekolah menderita gangguan perkembangan berbagai masalah perkembangan anak, seperti keterlambatan motorik, bahasa dan perilaku sosial dalam beberapa tahun terakhir ini semakin meningkat. (WHO, 2014)

Menurut data yang di dapat sekitar 30 juta anak-anak dan remaja di Indonesia merupakan pengguna internet dan media digital saat ini menjadi pilihan utama saluran komunikasi yang mereka gunakan, di Indonesia terdapat $80 \%$ responden yang merupakan pengguna internet dengan bukti kesenjangan digital yang kuat antara mereka yang tinggal di wilayah perkotaan dan lebih sejahterahanya $13 \%$ sedangkan mereka yang tinggal di daerah pedesaaan dan kurang sejahtera menyumbang jumlah 87\%. (UNICEF, 2014)

Kebiasaan anak menggunakan gadget akan merusak kemampuan berkosentrasi memang mengasyikkan, tapi akhirya terbiasa begitu, sehingga pada waktu seorang anak harus fokus terhadap sesuatu hal, akhirnya menjadi susah untuk fokus. (Kominfo, 2018). Menurut direktur jendral informasi dan komunikasi dan informatika pada tahun. 2015 pengguna posel di tanah air di perkirakan ada 270 juta gadget digunakan oleh penduduk indonesia yang sudah melebihi indonesia yang hanya sekitar 250 juta jiwa, sedangkan pengguna gadget di Indonesia di dominasi oleh anak-anak sebesar $80 \%$ (kemenkominfo, 2014). Untuk data tahun 2017 jumlah pengguna internet telah mencapai 143, 26 juta jiwa atau setara dengan 54, 68 persen dari total jumlah penduduk indonesia. Jumlah tersebut menunjukan kenaikan sebesar 10. 56 juta jiwa dari hasil survey pada tahun 2016. Demikian di umumkan asosiasi penyelenggara jasa internet indonesia (APJII) setelah melakukan survei penetrasi dan pelaku pengguna internet di Indonesia. (Kominfo, 2017)

Dalam survey yang dilakukan oleh The Asian parent Insights pada lingkup studi kawasan Asia Tenggara dengan melibatkan setidaknya 2.417 orang tua yang memiliki gadget dan anak dengan usia 3-8 tahun pada 5 negara yakni Singapura, Thailand, Philipina, Malaysia dan Indonesia. Dengan jumlah sampel orang tua tersebut, di peroleh 3.917 sampel anak-anak dengan usia 3-8 tahun. Dari 98\% responden anakanak usia 3-8 tahun pengguna gadget tersebut $67 \%$ di antaranya menggunakan gadget milik orang tua mereka $18 \%$ lainnya menggunakan gadget milik saudara atau keluarga, dan $14 \%$ sisanya menggunakan gadget milik sendiri. Angka kejadian masalah perkembangan pada anak di indonesia antara 13-18 \%. (Triastuti, 2018)

Menurut survey Badan Pusat Statistik (BPS) di Provinsi Sulawesi Utara pengguna seluler usia 5 tahun ke atas pada tahun 2017 data yang di dapatkan sebanyak $61,95 \%$ pada anak laki-laki sebanyak $62,02 \%$ dan anak perempuan sebanyak 61, 87\%. (Badan Pusat Statistik, 2017)

Perkembangan teknologi semakin berkembang dengan pesat sesuai dengan perkembangan zaman, teknologi muncul dalam berbagai fitur dari teknologi selalu baru dari hari kehari. (Witarsa et al., 2018). Aplikasi teknologi informasi dan komunikasi yang mrupakan pengembangan teknologi, di antaranya adalah gadget. Gadget merupakan teknologi yang sangat populer sekarang ini, orang dewasa maupun anakanak menggunakan gadget, dimana banyak produk-produk gadget yang menjadikan 
anak-anak sebagai target pasar mereka dan anak-anak kini telah menjadi konsumen aktif pengguna gadget. (Palar et al., 2018) Hampir semua kalangan masyarakat memiliki gadget, faktanya gadget tak hanya digunakan oleh orang dewasa atau lanjut usia. Di kalangan remaja (12-21 tahun) dan dewasa atau lanjut usia (60 tahun ke atas), tapi pada anak-anak (7-11 tahun) dan lebih ironisnya lagi gadget digunakan untuk anak-anak (3-6 tahun) yang seharusnya belum layak menggunakan gadget. (Novitasari, 2016)

Perkembangan dan kemajuan teknologi komunikasi semakin membuat orang tua melakukan pengawasan lebih ekstra lagi, jenis dan fungsi gadget yang semakin beranekaragam membuat anak dimanjakan oleh gadget mereka dan tidak heran banyak anak ataupun pelajar sekolah yang menenteng ponsel ataupun tablet kemanamana, ini menjadi kekhawatiran bagi beberapa orang tua karena takut anak mereka tergelincir ke hal-hal yang negatif, apalagi smarthphone yang semakin canggih. Fungsi ponsel bukan lagi menelpon dan mengirim pesan, tetapi juga mengirim gambar dan foto, browser internet, nonton video, main game, merekam audio dan video, eksis di media sosial dan masih banyak lagi. (Fahriantini, 2016)

Dampak negatif penggunaan gadget, yaitu dapat mengganggu kesehatan menganggu perkembangan anak, mempengaruhi perilaku anak dan penurunan konsentrasi belajar. (Anggraeni \& Hendrizal, 2018)

Berdasarkan pengambilan data awal di desa Dulangon Kecamatan Lolak pada tahun 2019 di dapatkan data jumlah kepala keluarga (KK) sebanyak 200 orang dan data jumlah anak usia sekolah sebanyak 51 anak.

Hasil wawancara dari 10 keluarga yang di lakukan di desa Dulangon Kecamatan Lolak terdapat 7 keluarga yang mengakui anaknya sering menggunakan gadget sepanjang hari sehingga mengalami mata perih, anak juga menunjukan kurangnya melakukan aktivitas atau bergerak dan hanya selalu terpaku di depan gadget, anak tersebut juga sering tidur larut malam dan juga sering menunjukan perilaku emosi yang melawan saat orang tua membatasi penggunaan gadget maupun saat orang tua menyuruh untuk melakukan sesuatu. Kondisi ini dapat membuat keluarga khawatir anaknya menjadi malas dan ketergantungan terhadap gadget sehingga penting peran keluarga yang ekstra dalam mendidik anak agar tidak terjerumus ke hal-hal yang berdampak negatif.

\section{Metode Penelitian}

Desain penelitian ini menggunakan penelitian deskriptif analitik dan menggunakan pendekatan cross sectional yaitu pengumpulan data dua variabel dilakukan dalam satu waktu (Donsu, 2017). Penilitian ini telah dilaksanakan di Desa Dulangon Kecamatan Lolak. Penelitian ini telah dilaksanakan pada bulan April s/d Mei 2019. Populasi adalah wilayah generalisasi yang terdiri atas: obyek/subyek yang mempuyai kualitas dan karakteristik tertentu yang di tetapkan oleh peneliti untuk dipelajari dan kemudian di tarik kesimpulannya. Populasi dalam penelitian ini adalah semua anak usia sekolah di Desa Dulangon Kecamatan Lolak berjumlah 51 anak.

Jumlah populasi sudah diketahui jumlahnya maka pengambilan jumlah sampel penelitian ini menggunakan pengambilan sampel adalah teknik total sampling yaitu mengambil sampel dari seluruh populasi, Jadi besar sampel adalah 51 anak. Analisis data dilakukan dalam bentuk univariat dan bivariat.

Analisa univariat untuk mendapatkan gambaran distribusi frekuensi dari variabel-variabel penelitian yaitu peran keluarga dan dampak negatif penggunaan gadget pada anak. Analisis dilakukan dengan statistik deskriptif berupa distribusi frekuensi. Analisa bivariat bertujuan untuk mengetahui ada tidaknya hubungan yang bermakna antara variabel bebas peran keluarga dan dampak negatif penggunaan gadget pada anak. Analisis dilakukan dengan uji Chi-Square pada analisis ini dilakukan 
pengujian risk estimate agar didapatkan OR (odds ratio). OR diperlukan untuk menilai peluang dari variabel bebas terhadap variabel terikat.

\section{Hasil Penelitian}

\section{Karakteristik Responden.}

Tabel 1. Distribusi Berdasarkan Usia Responden

\begin{tabular}{ccc}
\hline Usia Responden & $\mathbf{N}$ & $\%$ \\
\hline 20-30 Tahun & 1 & 2.0 \\
31-40 Tahun & 29 & 56.9 \\
41-50 Tahun & 21 & 41.2 \\
\hline Total & $\mathbf{5 1}$ & $\mathbf{1 0 0 . 0}$ \\
\hline
\end{tabular}

Distribusi responden diatas, dapat dijelaskan bahwa dari 51 responden, sebagian besar Usia 31-40 tahun (56,9\%) atau sebanyak 29 responden, diikuti Usia 41-50 tahun adalah dengan jumlah responden 21 orang $(41,2 \%)$ dan Usia 20-30 tahun dengan jumlah responden1 responden $(20,0 \%)$.

Tabel 2. Distribusi Berdasarkan Jenis Kelamin

\begin{tabular}{ccc}
\hline Jenis Kelamin & $\mathbf{n}$ & $\%$ \\
\hline Laki-Laki & 20 & 39.2 \\
Perempuan & 31 & 60.8 \\
\hline Total & $\mathbf{5 1}$ & $\mathbf{1 0 0 . 0}$ \\
\hline
\end{tabular}

Distribusi responden diatas, dapat dijelaskan bahwa dari 51 responden, sebagian besar dengan jenis kelamin perempuan $(60,8 \%)$ atau sebanyak 31 responden, diikuti dengan jenis kelamin laki-laki adalah dengan jumlah responden 20 orang $(39,2 \%)$.

Tabel 3. Distribusi Berdasarkan Pekerjaan

\begin{tabular}{ccc}
\hline Pekerjaan Responden & $\mathbf{n}$ & $\%$ \\
\hline Petani & 16 & 31.4 \\
IRT & 29 & 56.9 \\
Wiraswasta & 5 & 9.8 \\
TNI & 1 & 2.0 \\
\hline Total & $\mathbf{5 1}$ & $\mathbf{1 0 0}$ \\
\hline
\end{tabular}

Distribusi responden berdasarkan pekerjaan, sebagian besar bekerja sebagai Ibu rumah tangga 29 responden (56.9\%) kedua petani yaitu 16 responden (31.4\%) ketiga wiraswasta yaitu 5 responden $(9.8 \%)$ dan yang paling kecil TNI yaitu 1 responden $(2.0 \%)$.

Tabel 4. Distribusi Berdasarkan Usia Anak

\begin{tabular}{ccc}
\hline Usia Responden & $\mathbf{N}$ & $\%$ \\
\hline 10 Tahun & 23 & 45.1 \\
11 Tahun & 20 & 39.2 \\
12 Tahun & 8 & 15.7 \\
\hline Total & $\mathbf{5 1}$ & $\mathbf{1 0 0}$ \\
\hline
\end{tabular}


Distribusi responden diatas, dapat dijelaskan bahwa dari 51 responden, sebagian besar Usia 10 tahun (45,1\%) atau sebanyak 23 responden, diikuti Usia 11 tahun adalah dengan jumlah responden 20 orang $(39,2 \%)$ dan Usia 12 Tahun dengan jumlah responden 8 responden (15,7\%).

Tabel 5. Distribusi Berdasarkan Kelas Anak

\begin{tabular}{ccc}
\hline Kelas Responden & $\mathbf{n}$ & $\%$ \\
\hline Kelas 4 & 16 & 34.1 \\
Kelas 5 & 9 & 17.6 \\
Kelas 6 & 26 & 51.0 \\
\hline Total & $\mathbf{5 1}$ & $\mathbf{1 0 0}$ \\
\hline
\end{tabular}

Distribusi responden berdasarkan pekerjaan, sebagian besar kelas 6 yaitu 26 responden $(51,0 \%)$ kedua kelas 4 yaitu 16 responden $(34,1 \%)$ dan yang paling kecil kelas 5 yaitu 9 responden (17,6\%).

2. Distribusi Kategori Variabel Penelitian

Tabel 6. Variabel Peran Keluarga

\begin{tabular}{ccc}
\hline Peran Keluarga & $\mathbf{n}$ & $\%$ \\
\hline Kurang Baik & 25 & 49.0 \\
Baik & 26 & 51.0 \\
\hline Total & $\mathbf{5 1}$ & $\mathbf{1 0 0}$ \\
\hline
\end{tabular}

Distribusi responden berdasarkan variabel Peran Keluarga, dapat dilihat bahwa sebanyak 26 responden atau 51,0 peran keluarga baik dan 25 responden $(49,0 \%)$ peran keluarga kurang baik dari 51 responden (100\%)

Tabel 8. Variabel Dampak Negativ Pengunaan Gadget Pada Kesehatan Mental

Anak

Dampak Negativ

Penggunaan Gadget

Pada Kesehatan Mental

n $\quad \%$

Anak

\begin{tabular}{ccc}
\hline Tidak & 23 & 45.1 \\
Ya & 28 & 54.9 \\
\hline Total & $\mathbf{5 1}$ & $\mathbf{1 0 0}$ \\
\hline
\end{tabular}

Distribusi responden berdasarkan variabel dampak negatif penggunaan gadget pada anak, dapat dilihat bahwa dampak penggunaan gadget pada anak dalam kategori ya terbanyak berjumlah 28 orang $(54.9 \%)$ dan tidak yaitu berjumlah 23 orang $(45.1 \%)$.

3. Hasil Tabulasi Silang peran keluarga dengan dampak negatif penggunaan gadget pada kesehatan mental anak.

\begin{tabular}{|c|c|c|c|c|c|c|c|c|}
\hline \multirow{3}{*}{$\begin{array}{l}\text { Peran } \\
\text { Keluarga }\end{array}$} & \multicolumn{4}{|c|}{$\begin{array}{l}\text { Dampak Penggunaan Gadget } \\
\text { Pada Kesehatan Mental Anak }\end{array}$} & \multirow{2}{*}{\multicolumn{2}{|c|}{ Total }} & \multirow[t]{3}{*}{ OR } & \multirow{2}{*}{$\begin{array}{c}P \\
\text { Value }\end{array}$} \\
\hline & & & & & & & & \\
\hline & $n$ & $\%$ & $\mathbf{N}$ & $\%$ & $n$ & $\%$ & & \\
\hline $\begin{array}{l}\text { Kurang } \\
\text { Baik }\end{array}$ & 0 & 0 & 25 & 49.0 & 25 & 100 & 8.667 & 0.000 \\
\hline Baik & 23 & 45.1 & 3 & 5.9 & 26 & 100 & & \\
\hline Total & 23 & 45.1 & 28 & 54.9 & 51 & 100 & & \\
\hline
\end{tabular}

Hasil tabulasi silang memperoleh nilai $p=0,000$, yang menyatakan bahwa ada hubungan antara peran keluarga dalam menghindari dampak negatif penggunaan gadget pada kesehatan mental anak usia sekolah . Nilai OR=8,667.

Peran Keluarga Dalam Menghindari Dampak Negatif Penggunaan Gadget Pada Kesehatan Mental Anak Usia Sekolah Di Desa Dulangon (Moh. Rizki Fauzan) 


\section{PEMBAHASAN}

Hubungan Peran Keluarga Dalam Menghindari Dampak Negatif Penggunaan Gadget Pada Kesehatan Mental Anak di Desa Dulangon Kecamatan Lolak.

Peran keluarga Dapat disimpulkan bahwa sebagian besar peran keluarga kebanyakan tergolong baik. Oleh karena itu orang tua seharusnya menjadi cerminan bagi anak mereka. Hal ini di mulai dari usia dini dimana orang tua harus menjauhkan jangkauan anak dari gadget. Kemudian sampai pada usia yang sewajarnya, orang tua baru dapat memberikan kepercayaan pada mereka untuk menggunakan gadget dalam keadaan dan waktu tertentu, dengan adanya pengawasan dan bimbingan penuh. Jika anak sudah terlanjur dengan gadget-nya orang tua dapat melakukan pendekatan dengan memberikan hiburan kebersamaan yang sekiranya membuat dia lupa dengan gadget-nya.

(Nuraedah, 2016) mengatakan orang tua juga harus seperti gadget bagi anak dalam membiasakan diri menjadi jawaban atas semua pertanyaan dan masalah yang di alami anak mereka. Lebih sering berbincang dan menemani anak dalam belajar, berbincang, berlibur, berolahraga, serta memilihkan permainan dan hiburan yang mendidik tetapi, tidak membosankan bagi merekA.

Eby (2017) bahwa orang tua bertanggung jawab melakukan pengawasan dan pendampingan penggunaan gadget pada anak, serta memastikan bahwa anak-anak menggunakan gadget untuk mengakses informasi-informasi sebagai bahan pelajarannya, orang tua juga melarang anak membawa gadget keluar rumah, menredupkan kecerahan layar gadget sebelum di pinjamkan kepada anak.

(Klftiyah et al., 2017) Menyebutkan bahwa salah satu peran orang tua dalam mendampingi penggunaan gadget pada anak sekolah adalah dengan cara menstimulasi perkembangan kognigtif melalui video youtube.

Dapat diketahui bahwa sebagian besar penggunaan gadget pada anak dengan dampak negatif yaitu mata perih, pusing, dan sering tidur larut malam. Oleh karena itu, di perlukan pengawasan dari orang tua untuk lebih memperhatikan penggunaan gadget pada anak karena dampak berdampak buruk.

Menurut penelitian sebelumnya, yang dilakukan oleh (Mediasyifa, 2014) disebutkan beberapa pengaruh buruk gadget terhadap anak, yaitu kesehatan kepribadian, pendidikan/prestasi serta tehadap keluarga dan masyarakat seorang anak yang menggunakan gadget dengan intensitas waktu yang berlebihan atau mengakibatan kerusakan pada mata, memberikan beban pada tulang leher dan tulang punggung yang menyebabkan insonmnia dan menyebabkan nomophobia pada perkembangan kepribadiannya anak merasa memiliki dunianya sendiri dan lebih agresif terhadap keluarga dan orang sekitarnya.

(Dani, 2014) Anak yang bermain game secara berlebihan akan menimbulkan dampak negatif bagi perkembangan kognitif. Dampak negatif game lebih dirasakan jika terjadi kecanduan bermain game. Apabila game dimainkan secara berlebihan anakanak tidak dapat mengerjakan tugas yang diberikan sekolah, tidak konsentrasi pada waktu proses pembelajaran, tidur di dalam kelas bahkan sampai bolos sekolah.

Pada salah satu penelitian oleh (Novitasari, 2016) penggunaan gadget pada siswa SD menyebutkan bahwa pemakaian gadget lebih menyenangkan dibandingkan dengan bermain dengan teman sebayanya. Hal ini tak lepas oleh berbagai aplikasi permainan yang terdapat pada gadget anak-anak ini, yang tentunya lebih menarik perhatian anak-anak ini dibandingkan dengan permainan-permaian yang terdapat di lingkungan sekitarnya. Selain itu juga, orangtua meng"iya"kan bahwa saat anakanaknya bermain gadget cenderung anak-anak ini diam di depan gadget-nya masingmasing tanpa mempedulikan dunia sekitarnya. Secara tidak sadar, anak-anak sudah mengalami ketergantungan menggunakan gadget. 
Hasil penelitian menunjukkan bahwa terdapat hubungan antara peran keluarga dalam menghindari dampak negatif penggunaan gadget pada anak usia sekolah di Desa Dulangon Kecamatan Lolak yang telah di buktikan secara statistik dengan uji statistik chi-square $=0.000$ yang berarti $p$ value $<0.05$. maka dapat di simpulkan bahwa $\mathrm{Ho}$ di tolak dan $\mathrm{Ha}$ di terima dimana hubungan tersebut terdapat korelasi negatif yang signifikan itu dapat dilihat bahwa semakin baik pula perilaku anak dalam penggunaan gadget.

Dalam penelitin ini terdapat 3 responden yang mendapat perilaku baik namun memiliki perilaku anak kurang baik hal ini bisa di sebabkan karena faktor lingkungan sekitar dalam proses perkembangan anak. Lingkungan merupakan faktor yang sangat penting tanpa adanya dukungan dan lingkungan maka proses perkembangan tidak akan berjalan baik. Ketika lingkungan dapat memberikan dampak yang lebih baik maka besar kemungkinan perilaku anak dapat terpenuhi oleh lingkungan tersebut.

Anak-anak lebih memilih bermain menggunakan gadget dari pada bermain dengan teman-teman di lingkungan sekitar tempat tinggalnya. Penggunaan gadget di karenakan tuntutan trend saat ini yang meuntut mereka untuk aktif dalam dunia internet, dunia sosial dan dimana gadget mampu menyajikan dimensi gerak, suara, warna dan lagu sekaligus selain itu, materi yang di sajikan dalam gadget sangat variatif. Anak dapat mengakses informasi beserta hiburan di dalam gadget. sehingga membuat anak-anak menjadi betah berlama-lama menggunakan gadget.

Orang tua juga terkadang telampau sering berpaling pada ponsel mereka membaca pesan, sosial media dan menonton video. Sebagian lagi gagal dalam membangun dan memelihara dengan baik aturan-aturan yang mereka buat sendiri bagi anak-anak dan keluarga. Di samping itu, sesungguhnya anak lebih sering meniru perilaku orang dewasa terlebih orang tuanya sendiri.

(Fathoni, 2017) Mmengatakan orang tua juga lebih fokus menggunakan gadget-nya dari pada berbincang dengan anak mereka.

Hubungan antara peran keluarga dalam menghindari dampak negatif penggunaan gadget pada anak dengan penggunaan gadget ini memperoleh hasil yang sama dengan dengan penelitian (Markustianto, 2017) apabila peran keluarga baik maka besar perilaku anak dalam menggunakan gadget juga baik, hal itu di karenakan orang tua banyak memberikan pengarahan bagimana menggunakan gadget yang tepat dan baik. Namun sebaliknya bila peran keluarga kurang baik maka perilaku anakpun akan kurang baik karena kurangnya penjelasan tentang bagaimana menggunakan teknologi dalam hal ini gadget untuk hal-hal yang baik.

Hasil penelitian sejalan juga dengan yang dilakukan oleh (Palar et al., 2018) dengan judul hubungan peran keluarga dalam menghindari dampak negatif penggunaan gadget pada anak di Desa Kiawa 2 Barat Kecamatan kawangkoaan Utara, menunjukkan bahwa ada hubungan peran keluarga dalam menghindari dampak negatif penggunaan gadget pada anak di Desa Kiawa 2 Barat Kecamatan kawangkoaan Utara dengan nilai $p=0,000$.

Namun hasil penelitian tidak sejalan dengan yang di lakukan oleh Nuredah (2016) yang diperoleh $p=0,0275$ yang menunjukan bahwa tidak adanya hubungan dimana dampak negatif gadget tidak hanya di pengaruhi oleh peran orang tua saja akan tetapi ada banyak faktor lain yang mempengaruhi seperti lingkungan, sekolah, ,media sosial, teman dan lain sebagainya. Hal ini ditujukan pada hasil koefisien determinasi data yang menunjukkan bahwa 1, 2\% variasi dari dampak gadget pada anak bisa di jelaskan oleh variasi dari peran orang tua sedangkan sisanya $98,8 \%$ di jelaskan oleh sebab-sebab lain.

Dengan demikian untuk menghindari dampak negatif gadget pada anak sangatlah diperlukan peran keluarga dalam penggunaan gadget yaitu dengan cara membatasi penggunaan gadget dengan semestinya sehingga kesehatan anak tidak terganggu.

Peran Keluarga Dalam Menghindari Dampak Negatif Penggunaan Gadget Pada Kesehatan Mental Anak Usia Sekolah Di Desa Dulangon (Moh. Rizki Fauzan) 


\section{Kesimpulan}

1. Diketahui peran keluarga dalam menghindari dampak negatif penggunaan gadget di Desa Dulangon Kecamatan Lolak sebagian besar peran keluarga baik yaitu 26 (51,0\%).

2. Diketahui dampak negatif penggunaan gadget pada anak di Desa Dulangon Kecamatan Lolak lebih banyak yaitu 28 (54, 9\%)

3. Teranalisis adanya hubungan signifikan peran keluarga dengan dampak negatif penggunaan gadget pada kesehatan mental anak dengan $p$ value 0,000 di Desa Dulangon Kecamatan Lolak

\section{Saran}

1. Manfaat bagi tempat penelitian

Berdasarkan penelitian yang dilakukan diharapkan keluarga dapat membatasi penggunaan gadget untuk menghindari dampak dari pengguna gadget tersebut dan memberikan sikap positif pada anak contonya memfokuskan anak pada kegiatan belajar saat di rumah dan tidak selalu memberikan gadget.

2. Manfaat bagi responden

Diharapkan penelitian ini menjadi pedoman atau bahan acuan bagi orang tua untuk menghindari dampak negatif pengguna gadget pada anak

3. Manfaat bagi Institusi

Diharapkan penelitian ini dapat menjadi referensi yang bermanfaat dalam mengembangkan ilmu pengetahuan bagi institusi yang dapat diaplikasikan pada masyarakat untuk menghindari dampak negatif penggunaan gadget

\section{Daftar Pustaka}

Akbar, H. (2020). Penyuluhan Dampak Perilaku Kecanduan Game Online Terhadap Kesehatan Remaja di SMA Negeri 1 Kotamobagu. Community Engagement \& Emergence Journal, 1(2), 42-47.

Anggraeni, A., \& Hendrizal, H. (2018). Pengaruh Penggunaan Gadget Terhadap Kehidupan Sosial Para Siswa. Pelita Bangsa Pelestari Pancasila, 13(1).

Badan Pusat Statistik. (2017). Statistik Usia 5 Tahun Ke Atas Yang Memiliki Telepon Seluler Sulawesi Utara.

Dani, R. W. R. (2014). Fenomena Kecanduan Game Online Pada Siswa.

Fahriantini, E. (2016). Peranan Orang Tua Dalam Pengawasan Anak Pada Penggunaan Blackberry Messenger di Al-azhar Shifa Budi Samarindai. EJournal Ilmu Komunikasi, 4(4).

Fathoni, A. R. (2017). Pengaruh Gadget Terhadap perkembangan Anak Usia Dini.

Klftiyah, I. N., Sagita, S., \& Baharudin, A. (2017). Peran Media Youtube Sebagai Sarana Optimalisasi Perkembangan Kognitif Pada Anak Usia Dini. Prosiding SEMNAS Penguatan Individu Di Era Revolusi Informasi, 3(1), 199-208.

Kominfo. (2017). Jumlah Penetrsi Pengguna Internet. Biro Humas Kementrian Komunikasi Dan Informasi.

Kominfo. (2018). Pengaruh Gadget Pada Anak. Kementrian Komunikasi Dan Informatika Republik Indonesia, 67-69.

Markustianto, D. (2017). Keluarga Sebagai Gadget bagi Anak. Jurnal Profesi, 7(17), 73-77.

Mediasyifa. (2014). Pengaruh Penggunaan Gadget Pada Remaja Terhadap Interaksi 
Sosial Remaja. Bogor. In Bogor: Institut Pertanian Bogor (pp. 34-35).

Novitasari, W. (2016). Dampak Penggunaan Gadget Terhadap Interaksi Sosial Anak Usia 5-6 Tahun. Jurnal PAUD Teratai, 5(3), 182-186.

Nuraedah. (2016). Peran Orang Tua Dalam Penanggulangan Dampak Negatif Handphone Pada Anak.

Palar, J. E., Onibala, F., \& Oroh, W. (2018). Hubungan Peran Keluarga Dalam Menghindari Dampak Negatif Penggunaan Gadget Pada Anak Dan Perilaku Anak Dalam Penggunaan Gadget Di Desa Kiawa 2 Barat Kecamatan Kawangkoan. Jurnal Keperawatan, 6(2), 12-21.

Triastuti, Y. (2018). Hubungan Bermain Gadget dengan tingkat perkembangan anak usia 4-6 tahun di taman kanak-kanak.

UNICEF. (2014). Perilaku Anak Dan Remaja Dalam Menggunakan Internet. Siaran Pers Kominfo, 21.

WHO. (2014). Dampak Negativ Gedget.

Witarsa, R., Hadi, R. S. M., Nurhananik, N., \& Haerani, N. R. (2018). Pengaruh Penggunaan Gadget Terhadap Kemampuan Interaksi Sosial Siswa Di Sekolah Dasar. PADAGOGIK: Jurnal Pendidikan Guru Sekolah Dasar, 6(1). 